\title{
BETULIN-3, 28-DIPHOSPHATE SALT COMPLEXES WITH AMINES AND THEIR ANTIOXIDANT ACTIVITY
}

\section{NINA B. MELNIKOVA ${ }^{1 *}$, DARINA S. MALYGINA ${ }^{1}$, OLGA N. SOLOVYEVA ${ }^{1}$, OLGA E. ZHILTSOVA ${ }^{1}$, VICTOR A. VASIN ${ }^{2}$, PAVEL S. PETROV' ${ }^{2}$ IRINA N. KLABUKOVA ${ }^{1}$}

${ }^{1}$ Department of Pharmaceutical Chemistry, Nizhny Novgorod State Medicinal Academy, Minin sq., 10/1, 603005 Nizhny Novgorod, Russia, ${ }^{2}$ Department of Chemistry, N. P. Ogarev Mordovian State University, Bolshevistskaya st. 68, 430005 Saransk, Russia

Email: melnikovanb@gmail.com

Received: 27 Oct 2017 Revised and Accepted: 21 Dec 2017

\section{ABSTRACT}

Objective: Studies of composition, stability and antioxidant properties of the betulin-3, 28-diphosphate complexes with dopamine and trisamine.

Methods: The betulin-3, 28-diphosphate (BDP) interaction with amines in a water-alcohol medium was studied by using spectral methods and potentiometric titration. Biochemical indexes such as catalase, superoxide dismutase (SOD), lactate dehydrogenase (LDH) activities and malondialdehyde (MDA) level were estimated in experiments on rats.

Results: BDP was synthesized using betulin by $\mathrm{POCl}_{3}$ treatment in the presence of pyridine in dioxane. The complexation of BDP with amines was confirmed by the ${ }^{31}$ P-NMR and FTIR-spectral data. The stoichiometry of BDP-dopamine complexes was equal to 2:1 and 4:1 and its complexes with trisamine were produced in the ratio 1:1 in a water-alcohol medium. The conditional stability constant $\mathrm{K}_{\text {st }}^{\prime}$ of the BDP-trisamine complex is $1130 \pm 55 \mathrm{~mol} \cdot \mathrm{l}^{-1}$. BDP-Tris complex improved SOD activity up to $30 \%$ and up to $105 \%$ in the presence of cytostatic-hydrazine sulfate. The MDA level in erythrocytes decreased up to $57 \%$ and in combination with cytostatics (5-fluorouracil and hydrazine sulfate)-up to $11-14 \%$. The catalase activity increased by 44-94\% and MDA level in erythrocytes decreased by 22-53\% under the action BDP-DA complexes that depends on the dose.

Conclusion: The BDP forms stable complexes with trisamine and dopamine that make it possible to use this compound as a component of drug delivery system for high toxicity cytostatics and for readily oxidized catecholamines. It has been shown that both its complexes with amines and the combination with cytostatics enhanced antioxidant activity in an experiment in vitro.

Keywords: Betulin-3,28-diphosphate salt complexes, Trisamine, Dopamine, Antioxidant activity

(C) 2018 The Authors. Published by Innovare Academic Sciences Pvt Ltd. This is an open access article under the CC BY license (http://creativecommons.org/licenses/by/4.0/) DOI: http://dx.doi.org/10.22159/ijpps.2018v10i2.23357

\section{INTRODUCTION}

Organic phosphates and phosphonates, which are capable to play a role of pro-drugs, are of interest for pharmaceutical and medicinal specialists [1]. Besides these compounds as salts significantly improve solubility and accordingly drug availability in the human body. For example, dexamethasone sodium phosphate in contrast to the parent molecule is very soluble in water and demonstrates the wide spectrum of the effect in injection form [2].

Recently natural bioactive substances modified by phosphate and phosphonate groups as potential drugs are intensively studied $[1,3,4]$. Betulin phosphonates as products of betulin modification extracted from birch bake showed high efficacy in the treatment of breast tumor (duct carcinoma) and brain (glioblastoma), melanoma and others in experiments in vitro [5].

Antimicrobial, antifungal, anti-inflammatory and antiviral activities of BDP were also demonstrated in experiments in vitro and in vivo [6-8]. Kaplun A. P. and others showed the ability of BDP to be as an inhibitor of complement being a regulating factor of general systemic diseases [9].

The important advantages of phosphate-containing molecules are high ability to interact with amines, amino acids, amino-and NHgroups of proteins [10] that by Cotton F. A. is a crucial property in life processes [11]. The nature of the interaction of phosphate with nitrogen-containing fragments is various and includes both covalent and hydrogen bonds as well salt formation as complexation due to non-specific non-covalent binding [12].

It will be expected that formation of the BDP salt complexes with amines improves its bioavailability. On the other hand, BDP may be a drug delivery agent of readily oxidizable amines such as catecholamines binding them in complexes by that to prevent amines oxidation. However, data on the betulin phosphate salt complexes with organic amines are lacking.

Trisamine (tris-oxomethyl-aminomethane) (Tris) may be as a component of the BDP salt complexes having two acid groups (fig. 1). Moreover, Tris has the ability to correct acidosis and ensure plasma iso-osmolality [13]. Tris is also used as an active pharmaceutical ingredient for bioavailability improving lipophilic drugs.

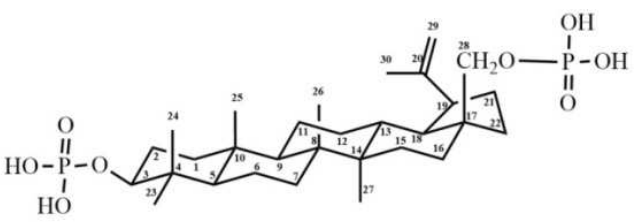

Betulin-3,28-diphosphate (BDP)<smiles>[NH3+]CCc1ccc(O)c(O)c1</smiles><smiles>NC(CO)(CO)CO</smiles>

Dopamine hydrochloride (DA)

Trisamine (Tris)

Fig. 1: Betulin-3, 28-diphosphate, dopamine hydrochloride and trisamine structures

In this paper we have studied the composition, stability and antioxidant properties of the BDP complexes with Tris and readily oxidizable catecholamines-dopamine hydrochloride (DA). 


\section{MATERIALS AND METHODS}

Ethanol 95\%, trisamine ("Sigma Aldrich", 154565-100 G), dopamine hydrochloride ("Sigma Aldrich", LRAA7131), $\mathrm{LiClO}_{4}$, purified water (resistivity $\geq 18 \mathrm{M} \Omega \cdot \mathrm{cm}$, "Millipore"). Betulin was isolated from Betula Pendula bark by the methods [14].

\section{Synthesis of betulin-3,28-diphosphate (BDP)}

$6.0 \mathrm{~g}(13.56 \mathrm{mmol})$ of betulin was solved in the mixture of 120 $\mathrm{ml}$ of dioxane and $7.08 \mathrm{ml}$ of pyridine $(81.6 \mathrm{mmol})$ in a threeneck flask at room temperature. $7.56 \mathrm{ml}$ of $\mathrm{POCl}_{3}(81.6 \mathrm{mmol})$ in
$60 \mathrm{ml}$ of dioxane was added to betulin solution dropwise into the flask at control temperature (up to $25{ }^{\circ} \mathrm{C}$ ) then the reaction mixture was stirred during $24 \mathrm{~h} .1000 \mathrm{~g}$ of water mixture and ice was added to the reaction mixture and then the white precipitate was filtered and washed several times by water. A wet sediment containing $25 \%$ of water was isolated that corresponds to betulin-3,28-diphosphate hydrate (betulin-3,28-diphosphate . $\mathrm{xH}_{2} \mathrm{O}$, where $\left.\mathrm{x}=8-9\right)$. IR-spectrum $\left(\mathrm{KBr}, \mathrm{cm}^{-1}\right): 3421$ brd. $(v \mathrm{OH})$, 1641 wk. $(v \mathrm{P}=0, v \mathrm{C}=\mathrm{C}), 1240$ brd. $(\delta \mathrm{P}=0), 1031$ brd., $973 \mathrm{brd}$. ( $v$ C-O), 501 nw. ( $v$ P-O). The BDP ${ }^{13}$ C-NMR spectrum (TMS, DMSO-d $6, \delta, p p m)$ :

\begin{tabular}{|c|c|c|c|c|c|c|c|c|c|c|c|}
\hline № & $\begin{array}{l}\delta, \\
\text { ppm }\end{array}$ & № & $\begin{array}{l}\delta, \\
\text { ppm }\end{array}$ & № & $\delta, \mathrm{ppm}$ & № & $\delta, \mathrm{ppm}$ & № & $\begin{array}{l}\delta, \\
\text { ppm }\end{array}$ & № & $\delta, \mathrm{ppm}$ \\
\hline $\mathrm{C} 1$ & 38.71 & $\mathrm{C} 2$ & 28.27 & C3 & 83.32 & $\mathrm{C} 4$ & 38.93 & $\mathrm{C} 5$ & 55.25 & C6 & 18.36 \\
\hline C7 & 36.93 & $\mathrm{C} 8$ & 40.84 & C9 & 50.04 & C10 & 37.42 & C11 & 20.77 & C12 & 25.18 \\
\hline C13 & 37.10 & C14 & 42.66 & C15 & 26.92 & C16 & 29.31 & C17 & 47.11 & C18 & 47.62 \\
\hline C19 & 48.46 & $\mathrm{C} 20$ & 150.31 & C21 & 29.46 & $\mathrm{C} 22$ & 34.13 & $\mathrm{C} 23$ & 28.53 & $\mathrm{C} 24$ & 16.06 \\
\hline $\mathrm{C} 25$ & 15.27 & $\mathrm{C} 26$ & 16.51 & $\mathrm{C} 27$ & 14.92 & $\mathrm{C} 28$ & 63.60 & $\mathrm{C} 29$ & 110.28 & C30 & 19.19 \\
\hline
\end{tabular}

The BDP ${ }^{1} \mathrm{H}-\mathrm{NMR}$ spectrum (TMS, DMSO-d $\left.\mathrm{d}_{6}, \delta, \mathrm{ppm}\right): 0.68-1.99\left(42 \mathrm{H}, 6 \mathrm{CH}_{3},\left(\mathrm{CH}_{2}\right) \mathrm{n} . \mathrm{m}.\right), 2.35$ (1H at C19, two t.), 3.70 (1H at C3, =CHOP, two t.), 3.95 and 3.52 (2H at $\mathrm{C} 28, \mathrm{CH}_{2} \mathrm{OP}$, two d.), 4.55, 4.68 (2H at C29, $\mathrm{CH}_{2}=\mathrm{C}, 2 \mathrm{~s}$.), 5.72 (protons in phosphate groups $\mathrm{O}-\mathrm{P}(\mathrm{OH})_{2}$, broad diffuses.).

UV-spectra were recorded by «UV-1800» (Shimadzu, Japan). IRspectra were recorded on «IR Prestige-21» (Shimadzu, Japan) in the range of 4000-500 $\mathrm{cm}^{-1}$ (tabl. KBr). RP-HPLC-analysis were carried out on «LC-20Avp» (Shimadzu, Japan) with UV-detection, the column is Discovery C18 ( $25 \mathrm{~cm} \times 4.6 \mathrm{~mm}, 5 \mu \mathrm{m}$, Supelco), retention time $\tau$ equal to $5.19 \mathrm{~min} .{ }^{13} \mathrm{C},{ }^{1} \mathrm{H},{ }^{31} \mathrm{P}-\mathrm{NMR}$ spectra were recorded by using NMR-spectrometer «JNM-ECX400» (Jeol, Japan), DMSO-d 6 , $\mathrm{CDCl}_{3}$, $\mathrm{D}_{2} \mathrm{O} ; 101,400$ and $202.46 \mathrm{MHz}$, respectively.

\section{Biological activity}

Biological activity in vitro was studied by using blood stabilized with sodium citrate (1:9). Antioxidant properties were estimated using the MDA level in plasma and erythrocytes by the method of M. Uchiyama, M. Mihara [15], using catalase and SOD (EC 1.11.1.6, 1.15.1.1) activities. The energy metabolism in erythrocytes was studied using the catalytic activity of LDH (EC 1.1.1.27) in the direct (substrate-50 mmol sodium lactate) and reverse (substrate-23 mmol sodium pyruvate) reactions $[16,17]$.

\section{RESULTS AND DISCUSSION}

Consecutive ionization stages of phosphoric residues of BDP lead to the splitting of two protons per phosphate group while the main process proceeds in the first stage (fig. 2).
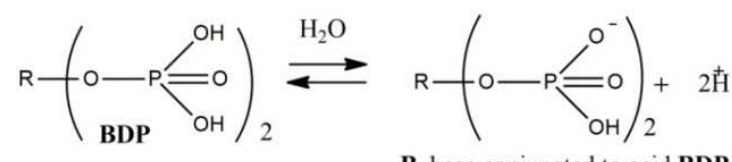

B, base conjugated to acid BDP
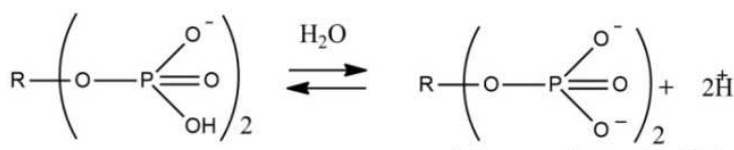

two-acid base conjugated to BDP

Fig. 2: The scheme of betulin-3, 28-diphosphate ionization in water-alcohol medium

The amphoteric ion B can be considered both acid and conjugated base to this acid. This ion can give a proton away in the aqueous solution as an acid or to accept one as a base. Acid-base properties of BDP were demonstrated by comparison with its UV-spectra in alcohol, water-alcohol, alcohol solution of $\mathrm{H}_{2} \mathrm{SO}_{4}$, in aqueous solutions of $\mathrm{NaOH}$ and in BDP solutions at constant ionic strength produced by $1 \cdot 10^{-2} \mathrm{M} \mathrm{LiClO}_{4}$ (fig. 3 , table 1 ).

Table 1: The influence of medium type on the BDP UV-spectra

\begin{tabular}{|c|c|c|c|}
\hline Conditions & $\mathrm{C} \cdot 10^{4}, \mathrm{M}$ & A & $\varepsilon, \mathrm{l} \cdot \mathrm{mol}^{-1} \cdot \mathrm{cm}^{-1}$ \\
\hline $95 \%$ ethanol & 9.8 & 0.430 & 439 \\
\hline $95 \%$ ethanol, $\mathrm{LiClO}_{4}$ & 9.8 & 0.410 & 418 \\
\hline $4 \cdot 10^{-3} \mathrm{M}$ water solution $\mathrm{NaOH}$ & 9.8 & 0.410 & 418 \\
\hline $95 \%$ ethanol-water $(1: 1)$ & 4.9 & 0.294 & 588 \\
\hline $95 \%$ ethanol-water $(1: 1), \mathrm{LiClO}_{4}$ & 4.9 & 0.373 & 761 \\
\hline $0.02 \mathrm{M}$ ethanol solution $\mathrm{H}_{2} \mathrm{SO}_{4}$ & 9.8 & 0.650 & 663 \\
\hline
\end{tabular}

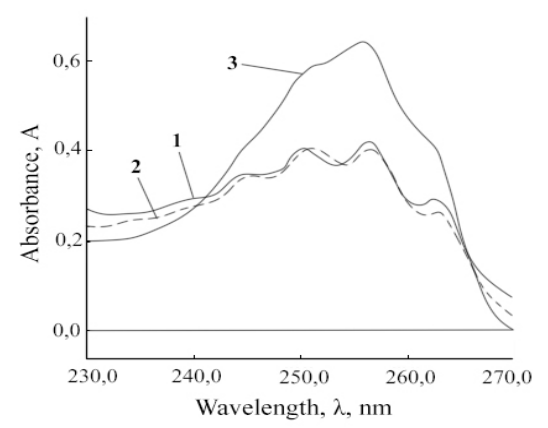

Fig. 3: UV-spectra of $1 \cdot 10^{-3} \mathrm{M}$ BDP solutions: 1 -in $95 \%$ alcohol; 2 -in $4 \cdot 10^{-3} \mathrm{M} \mathrm{NaOH}$ aqueous solution; 3-in $0.02 \mathrm{M} \mathrm{H}_{2} \mathrm{SO}_{4}$ alcohol solution
The UV-spectrum of $9.8 \cdot 10^{-4} \mathrm{M}$ BDP alkaline aqueous solution practically identifies to the one in $95 \%$ alcohol. The absorbance $\mathrm{A}$ $\left(\mathrm{n} \rightarrow \mathrm{p}^{*}\right.$ transfer) of BDP in $0.02 \mathrm{M} \mathrm{H}_{2} \mathrm{SO}_{4}$ solution at $\lambda_{\max }=256 \mathrm{~nm}$ was increased twice in comparison with $\mathrm{A}$ in the alcohol solution at the same BDP concentration. Similar increase An in UV-spectra in alcohol-water solution 1:1 was observed.

These indicate that BDP is mainly represented by base B both in $95 \%$ alcohol and $\mathrm{NaOH}$ aqueous solution but non-ionized BDP is the dominant form in the alcohol solution of $\mathrm{H}_{2} \mathrm{SO}_{4}$ or water-alcohol medium (1:1). The BDP molar extinction coefficient $\varepsilon$ is almost half as much than for its ionized form. The interaction of DA with BDP was studied both in the alcohol medium in which BDP mainly exists as an amphoteric base B and in the aqueous solution when BDP may be a more acidic or basic compound depending on the reaction conditions. 
The potentiometric titration curve of $8 \cdot 10^{-5} \mathrm{M}$ DA solution in water by $1 \cdot 10^{-3} \mathrm{M}$ BDP alcohol solution shows $\mathrm{pH}$ changes of DA solution from $\mathrm{pH} 5.4$ (without BDP) to 3.6 after BDP addition (fig. 4, curve 1). The data were compared with the blank experiment in water solutions containing the same BDP concentration (fig. 4, curve 2).

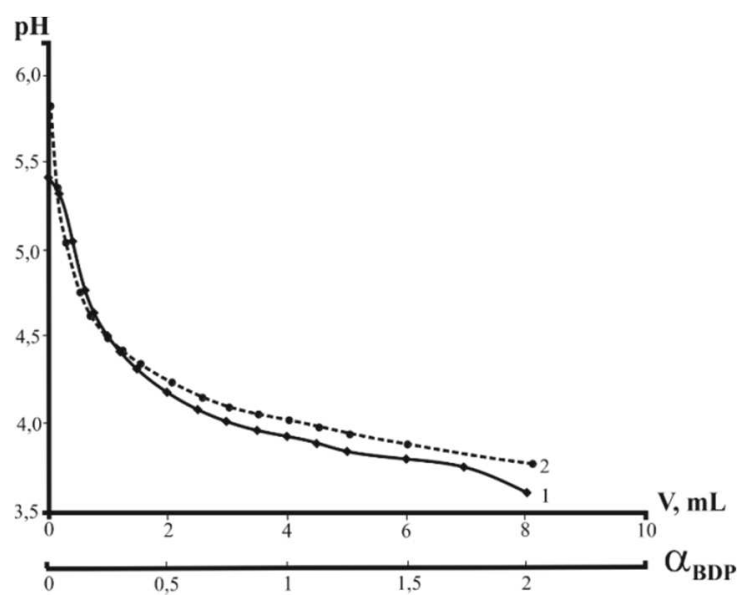

Fig. 4: The dependence of $\mathrm{pH}$ on molar ratio $\alpha_{\mathrm{BDP}}=\mathrm{n}_{\mathrm{BDP}} / \mathrm{n}_{\mathrm{DA}} \mathrm{pH}=$ $f\left(\alpha_{B D P}\right)$ in the BDP-DA system, $C_{D A}($ initial $)=$ const $=5.0 \cdot 10^{-5} \mathrm{M}$,

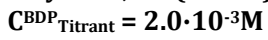

This result may be explained by the formation of BDP-anions with the following proton generation in the aqueous medium of DA and BDP-anions interaction with a protonated amine (fig. 5).

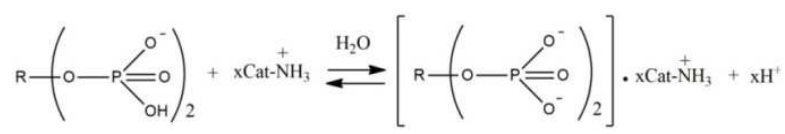

Fig. 5: The interaction of BDP-dianion with protonated amines *Cat means catechol fragment

Therefore, BDP as a weak acid or an amphoteric base B and DA as a weak base or an acid conjugated with DA are able to form the salts in water. However, it should be expected that the salt formation according to the scheme (fig. 5) is impossible in the neutral medium or in the buffer solution at $\mathrm{pH}$ near 7. For this purpose, the interaction of BDP with DA has studied in $95 \%$ ethanol as a neutral medium and in the phosphate buffer at pH 6.86 also. The processes were controlled by DA absorption band at $279 \mathrm{~nm}$ and by BDP absorption band at $256 \mathrm{~nm}$.

It has been shown that absorption $\mathrm{A}_{256}$ depended on DA molar ratio $\alpha=\frac{n_{D A}}{n_{B D P}}$ (fig. 6). At the first stage, $A_{256}$ has increased by half like in $0.02 \mathrm{M} \mathrm{H}_{2} \mathrm{SO}_{4}$ alcohol solution (section I) that characterizes the interaction of BDP-anion (base $\mathrm{B}$ ) with protonated $\mathrm{NH}_{3}{ }^{+}$-group of $\mathrm{DA}$ and the salt complexes formation.
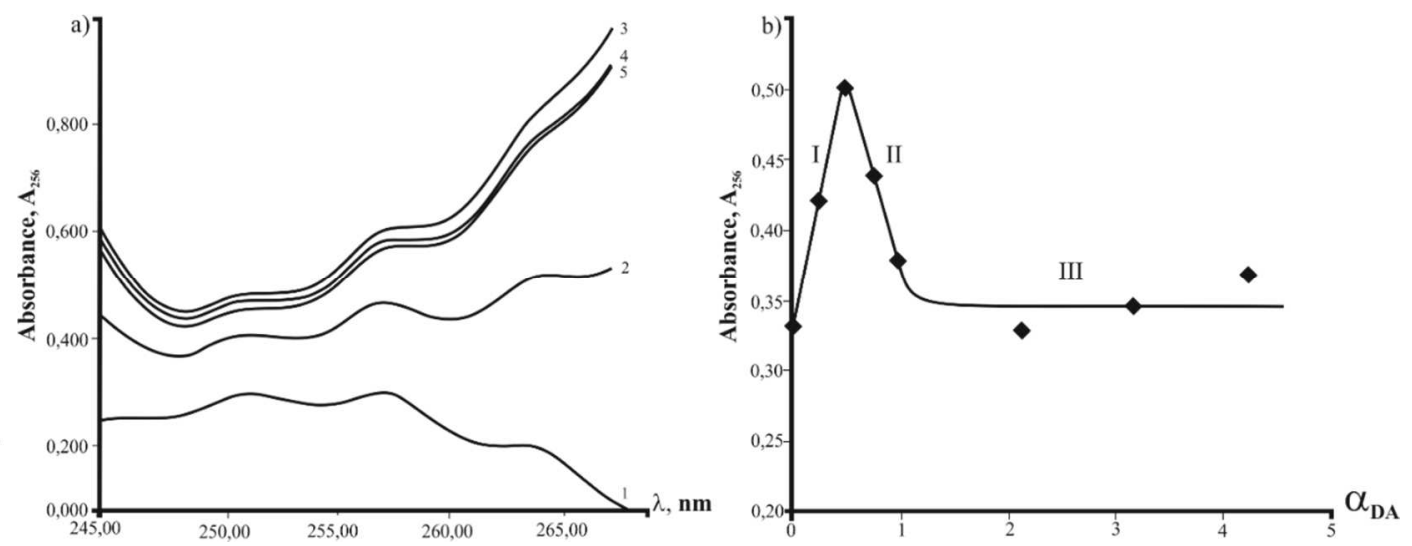

Fig. 6: UV-spectra of BDP-DA alcohol solutions at different molar ratio $\alpha_{D A}=n_{D A} / n_{B D P}, C_{B D P}=$ const $=8.4 \cdot 10^{-4} M$; the insert shows the dependence $A_{256}=f\left(\alpha_{D A}\right)$

The decreasing of $A_{256}$ to equilibrium value $A_{256}$ close to the value $A_{256}$ in the initial solution was observed (section II) and then $A_{256}$ was changed insignificantly by the $\alpha_{D A}$ increase when $\alpha>1$ (section III). The
$\mathrm{A}_{256}$ maximum and molar extinction coefficient $\varepsilon$ (table 2) correspond to the stoichiometry of the salt complex with the ratio of BDP to DA 2:1 and $\alpha_{D A}=0.5$ if the interaction proceeds in the alcohol solution.

Table 2: The data of UV-spectra to fig. 6

\begin{tabular}{|c|c|c|c|}
\hline № of curves & $\alpha=\frac{n_{D A}}{n_{B D P}}$ & $\mathbf{A}_{256} *$ & $\varepsilon, \mathrm{l} \cdot \mathrm{mol}^{-1} \cdot \mathrm{cm}^{-1}$ \\
\hline 1 & 0 & 0.332 & 395 \\
\hline 2 & 0.25 & 0.421 & 501 \\
\hline 3 & 0.5 & 0.505 & 601 \\
\hline 4 & 0.75 & 0.438 & 521 \\
\hline 5 & 1 & 0.380 & 452 \\
\hline
\end{tabular}

${ }^{*} \mathrm{~A}_{256}$ was estimated with the amendments of DA absorption

Spectrophotometric titration of $5.0 \cdot 10^{-5} \mathrm{M}$ DA solution in phosphate buffer at pH 6.86 by $2.0 \cdot 10^{-3} \mathrm{M}$ BDP alcohol solution was stepwise (fig. 7).

Two discontinuities in curve were observed at $\alpha_{\mathrm{BDP}}$ equaled to 2 and 4 , respectively. The dependence $\Delta \mathrm{A} / \Delta \mathrm{V}=\mathrm{f}\left(\mathrm{V}_{\mathrm{BDP}}\right)$ supported two stages process of this interaction that can be considered as complexes formation of BDP and DA with stoichiometry 2:1 and 4:1 accordingly.

Fig. 8 shows the probable structures of complex BDP and DA as the complex inclusion. 


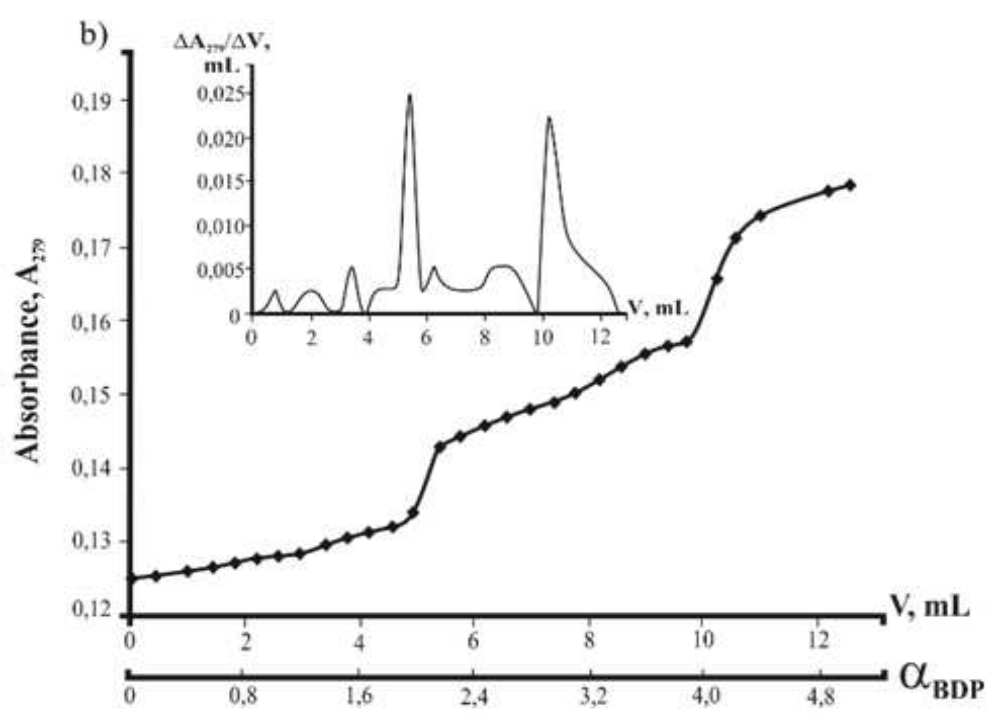

Fig. 7: The dependence of $A_{279}$ on molar ratio $\alpha_{B D P}=n_{B D P} / n_{D A}$ in the BDP-DA system, $C_{D A}($ initial $)=$ const $=5.0 \cdot 10^{-5} \mathrm{M}$, phosphate buffer,

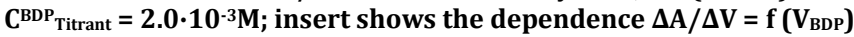
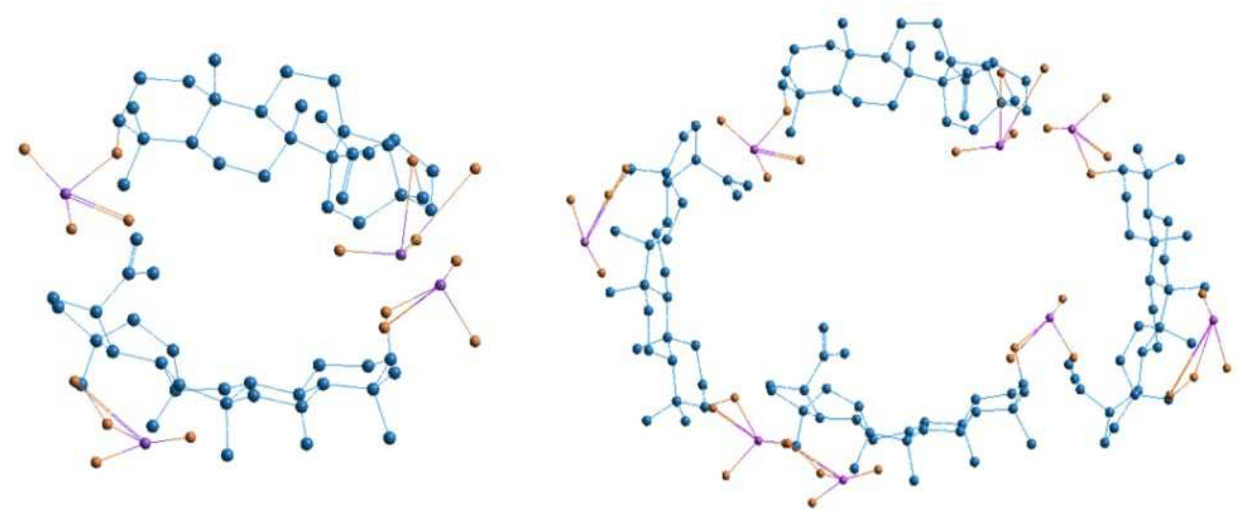

Fig. 8: Geometric visualization of BDP as a component of inclusion complexes formed by two and four molecules. Quantum-chemical calculations were provided by HyperChem 8.0 (semiempirical method AM1) [18]

The equilibrium in the first stage shifts toward base $\mathrm{B}$ when Tris aqueous solution was added to $9.8 \cdot 10^{-4} \mathrm{M}$ BDP alcohol solution at $\mathrm{pH}$ 2.5. So it may be proposed the absorption A will decrease. The data

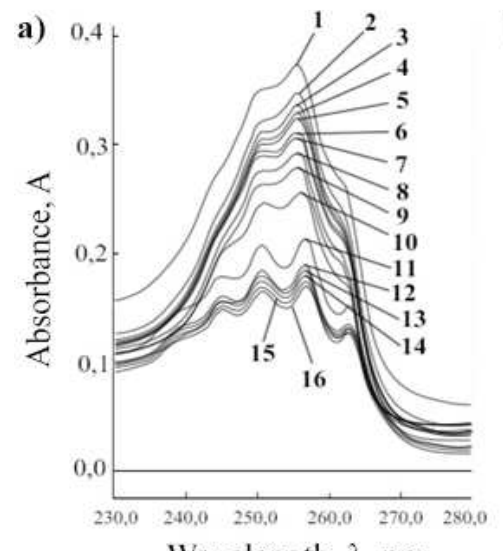

Wavelength, $\lambda, \mathrm{nm}$

(1) A will decrease. The data of fig. 9 and table 3 show the decrease of absorption A when molar ratio Tris: $\operatorname{BDP} \alpha=\frac{\mathrm{n}_{\text {Tris }}}{\mathrm{n}_{\mathrm{BDP}}}$ was increasing.

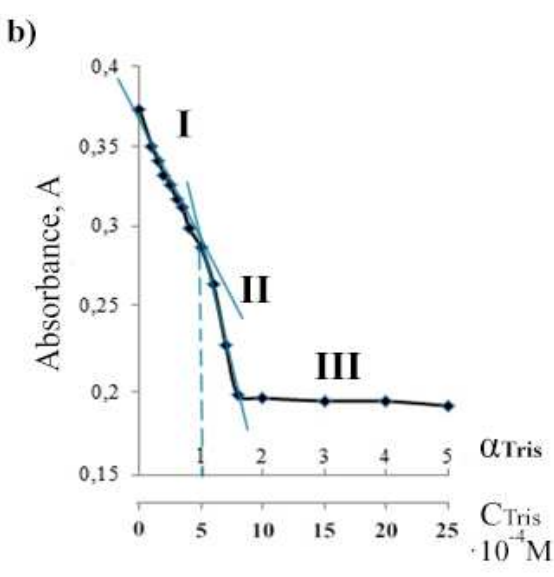

Fig. 9: UV-spectra of BDP and Tris mixtures at constant concentration $C_{B D P}=4.9 \cdot 10^{-4} M, C_{L i c l o 4}=1 \cdot 10^{-2} M$ : a) $A=f(\lambda)$; b) dependence of absorption $A$ on molar ratio $A=f(\alpha)$ or on Tris concentration $A=f\left(C_{\text {Tris }}\right)$ 
Table 3: The data of UV-spectra to fig. 9

\begin{tabular}{|c|c|c|c|c|c|c|c|c|c|}
\hline Curve № & $\alpha=\mathbf{n}_{\text {Tris }} / \mathbf{n}_{\text {BDP }}$ & $\begin{array}{l}\mathbf{C}_{\text {Tris, }} \\
\cdot \mathbf{1 0}^{4} \mathrm{M} \\
\end{array}$ & $\lambda, \mathbf{n m}$ & $\mathbf{A}$ & Curve № & $\boldsymbol{\alpha}=\mathbf{n}_{\text {Tris }} / \mathbf{n}_{\text {BDP }}$ & $\begin{array}{l}C_{\text {Tris, }} \\
\cdot 10^{4} \mathrm{M} \\
\end{array}$ & $\lambda, \mathbf{n m}$ & $\mathbf{A}$ \\
\hline 1 & 0 & 0 & 255.6 & 0.373 & 9 & 1.0 & 5 & 259.1 & 0.286 \\
\hline 2 & 0.2 & 1.0 & 255.7 & 0.350 & 10 & 1.2 & 6 & 259.2 & 0.263 \\
\hline 3 & 0.3 & 1.5 & 255.9 & 0.341 & 11 & 1.4 & 7 & 259.5 & 0.225 \\
\hline 4 & 0.4 & 2.0 & 256.0 & 0.332 & 12 & 1.6 & 8 & 260.0 & 0.194 \\
\hline 5 & 0.5 & 2.5 & 256.6 & 0.326 & 13 & 2.0 & 10 & 260.0 & 0.192 \\
\hline 6 & 0.6 & 3.0 & 256.9 & 0.317 & 14 & 3.0 & 15 & 260.0 & 0.190 \\
\hline 7 & 0.7 & 3.5 & 257.4 & 0.312 & 15 & 4.0 & 20 & 260.0 & 0.190 \\
\hline 8 & 0.8 & 4.0 & 258.9 & 0.299 & 16 & 5.0 & 25 & 260.0 & 0.187 \\
\hline
\end{tabular}

To establish Tris and BDP salt complex stoichiometry spectrophotometric titration was performed in accordance with Job's method (fig. 10).
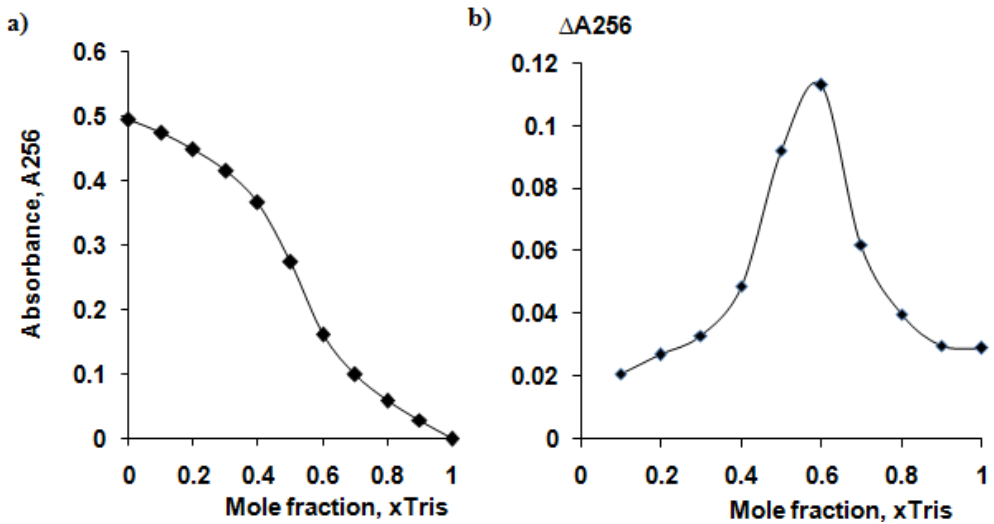

Fig. 10: Spectrophotometric titration in accordance to the Job's method. Concentration of initial solutions of BDP and Tris equal to 9.8-10-4M, $\mathrm{LiClO}_{4}$ concentration is $1 \cdot 10^{-2} \mathrm{M}$, water-alcohol medium: $\left.\left.a\right) A=f\left(x_{\text {Tris }}\right) ; b\right) \Delta A=f\left(x_{\text {Tris }}\right)$

Dependence $\Delta \mathrm{A}=\mathrm{f}\left(\mathrm{x}_{\text {Tris }}\right)$ shows that the BDP-Tris complex stoichiometry is $1: 1$ that corresponds to the ratio $\alpha=\frac{n_{\text {Tris }}}{n_{B D P}}$ which equales to 1 on section I of dependence $A=f(\alpha)$. Section III may be considered as «saturation» of BDP as an acid by Tris as a base in accordance with the molar-ratio method that was achieved at $\alpha$ close to 1.5 .
Salt character of the complex was confirmed by potentiometric titration of BDP alcohol solution by $0.5 \mathrm{M}$ Tris aqueous solution and comparison of the results with BDP titration by $0.2 \mathrm{M} \mathrm{NaOH}$ aqueous solution (fig. 11). BDP titration curve $\mathrm{pH}=\mathrm{f}(\mathrm{V})$ has the typical form of acid-base titration in both cases but BDP is titrated as a monobasic acid in case of Tris and dibasic one by $\mathrm{NaOH}$ titration.
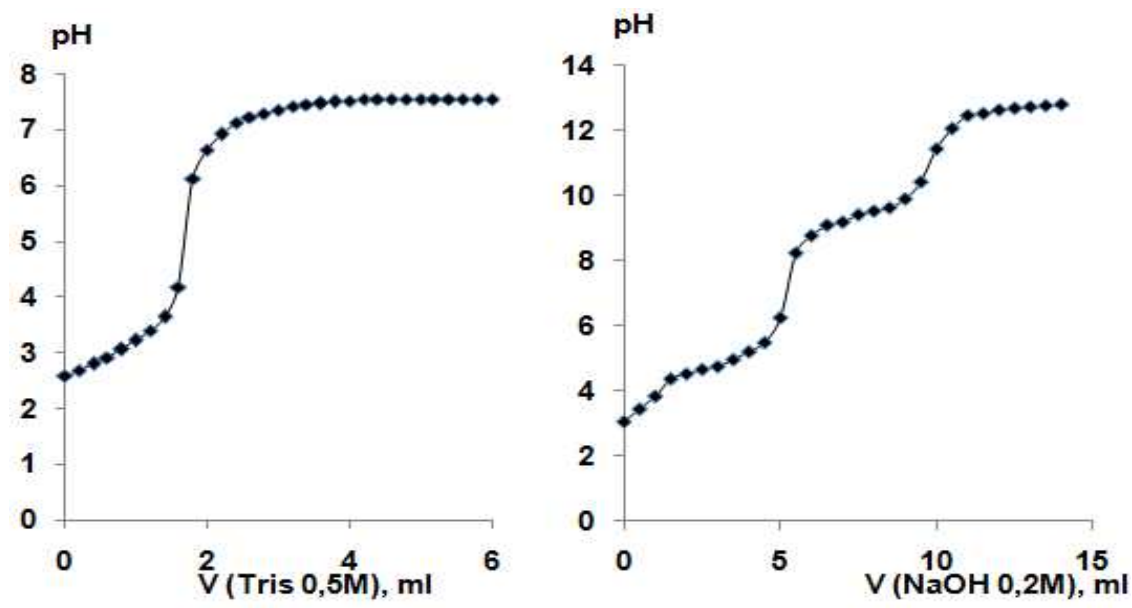

Fig. 11: Results of potentiometric titration of $10 \mathrm{ml} 0.05 \mathrm{M}$ betulin-3,28-diphosphate alcohol solution by base aqueous solutions: a) $0.5 \mathrm{M}$ trisamine; b) $0.2 \mathrm{M} \mathrm{NaOH}$

Formation of the BDP salt complexes with the amines was also studied using ${ }^{31} \mathrm{P}-\mathrm{NMR}-\mathrm{spectra}$ (fig. 12). The chemical shift of phosphate at C-3 of BDP equal to $-0.58 \mathrm{ppm}$ (doublet without decoupling from protons) varied in complex with DA (1:1) to +0.04 ppm but the chemical shift of phosphorus at $\mathrm{C}-28$ equal to +0.28 ppm (triplet without decoupling from proton)- up to $+0.94 \mathrm{ppm}$. Changes in the spectra insignificantly depend on the ratio of BDP: DA with increasing amine fraction (table 4). 

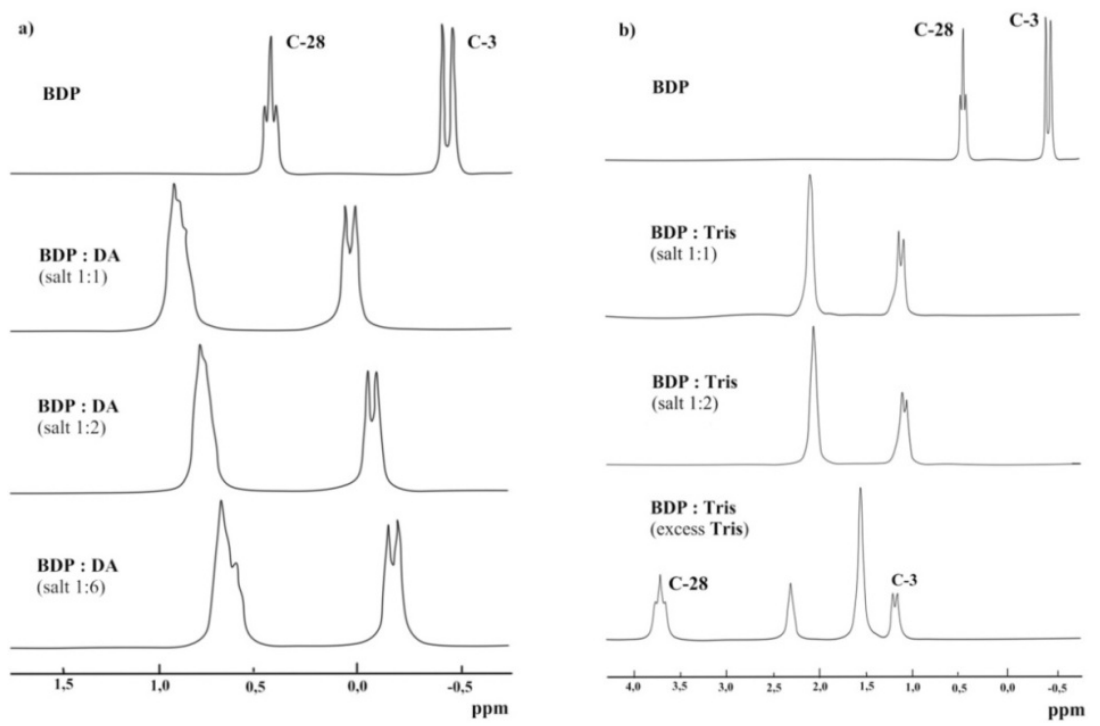

Fig. 12: ${ }^{31} \mathrm{P}-\mathrm{NMR}$-spectra of $\mathrm{BDP}$ and its complexes: a) with dopamine; b) with trisamine (DMSO- $\mathrm{d}^{6}$, standard $\mathrm{Ph} 3 \mathrm{P}, \delta=5.97 \pm 0.03$ ppm)

Table 4: The ${ }^{31}$ P-NMR-spectra data of BDP and its complexes with amines

\begin{tabular}{llllllll}
\hline $\boldsymbol{\delta}, \mathbf{p p m}$ & BDP & BDP: DA (1:1) & BDP: DA (1:2) & BDP: DA (1:6) & BDP: Tris (1:1) & BDP: Tris (1:2) & $\begin{array}{l}\text { BDP: Tris } \\
\text { (excess tris) }\end{array}$ \\
\hline $\mathrm{C}-28, \mathrm{~d}$ & -0.58 & 0.04 & -0.09 & -0.18 & 1.10 & 1.07 & 1.18 \\
$(\mathrm{~J}, \mathrm{~Hz})$ & $(8.15)$ & $(8.10)$ & $(8.10)$ & $(8.10)$ & $(8.45)$ & $(8.12)$ & $(8.10)$ \\
$\mathrm{C}-3, \mathrm{t}$ & 0.28 & 0.94 & 0.79 & 0.68 & 2.08 & 2.06 & 3.71 \\
\hline
\end{tabular}

The stronger changes in the spectra of BDP and Tris mixtures were noted. The phosphorus signal at C-3 in BDP shifted from $-0.58 \mathrm{ppm}$ up to $+1.10 \mathrm{ppm}$ and phosphorus at C-28- from $+0.28 \mathrm{ppm}$ up to $+2.08 \mathrm{ppm}$. The greatest changes with excess of Tris for BDP phosphorus at $\mathrm{C}-28(\delta=3.71 \mathrm{ppm})$ were observed. It should be noted that in all the cases stronger changes in the spectra occurred in phosphorus at C-28 of BDP. The FTIR-spectra data suggested BDP-Tris complex formation (fig. 13).

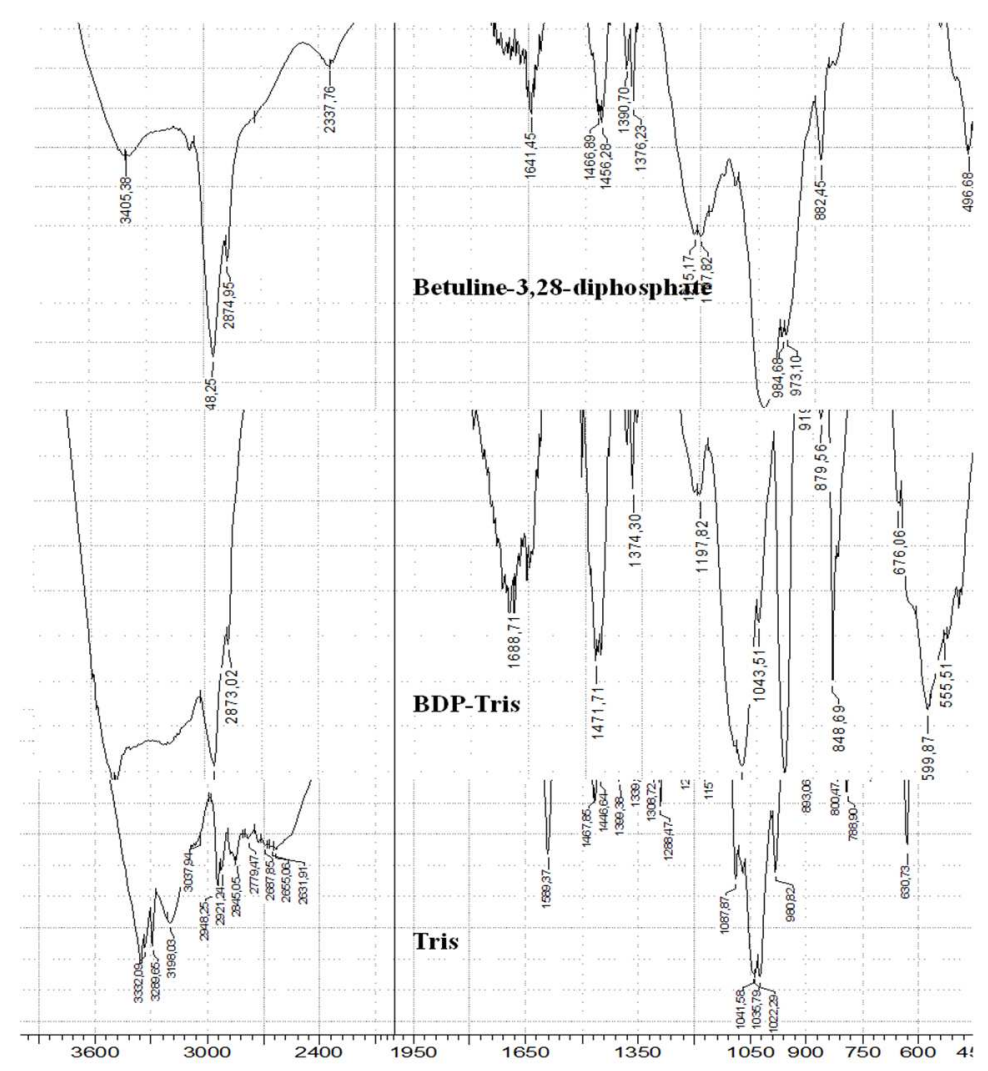

Fig. 13: FTIR-spectra of BDP (top), BDP-Tris complex (middle), Tris (bottom) 
The shape and the position of stretch vibration bands of C-O alcohol groups in Tris $\left(v 1041-1022 \mathrm{~cm}^{-1}\right)$ and C-O ester groups $(v 1031-973 \mathrm{~cm}$ $\left.{ }^{1}\right)$ in BDP were changed to a broad band in the region of 1070-970 $\mathrm{cm}^{-1}$. The stretch vibrations of P-O $\left(v 497 \mathrm{~cm}^{-1}\right)$ and $\mathrm{P}=0\left(v 1641 \mathrm{~cm}^{-1}, \delta 1215\right.$ $\mathrm{cm}^{-1}$ ) of BDP were dramatically changed. The hydrophilic index $\mathrm{I}=\mathrm{T}_{497}$ $500 / \mathrm{T}_{2948}$ equal to the ratio of transmission at $497 \mathrm{~cm}^{-1}$ to transmission at $2948 \mathrm{~cm}^{-1}$ ( $\mathrm{CH}, \mathrm{CH}_{2}, \mathrm{CH}_{3}$ of triterpene skeleton) was changed from 3.0 for initial BDP to 1.5-1.7 for BDP salt complex with Tris.

The ${ }^{31} \mathrm{P}-\mathrm{NMR}$ and IR-spectra data suggest that the interaction of BDP with amines is due to not only electrostatic forces leading to the salt nature of the complex (potentiometric spectrophotometric titration data) but also non-specific non-covalent interactions similar to interaction of phosphates as phytic acid with amines.

Consequently, the interaction of BDP with Tris can be regarded as the formation of salt complexes due to various intermolecular bonds.

This interaction between Tris and BDP at the ratio 1:1 can be considered as follows:

\section{$\mathrm{BDP}+$ Tris $\rightleftarrows$ Tris $\cdot \mathrm{BDP}$}

Stability constant of the salt complex will be expressed as:

$$
\mathrm{K}_{\mathrm{st}}=\frac{[\text { Tris } \cdot \mathrm{BDP}]}{[\text { Tris }][\mathrm{BDP}]}
$$

Where the equilibrium molar concentration of the components and the complex are indicated in square brackets.

Conditional stability constant will be expressed as:

$$
\mathrm{K}_{\mathrm{st}}^{\prime}=\frac{C_{\text {complex }}}{\left(C_{\mathrm{BDP}}^{\circ}-C_{\text {complex }}\right) \cdot\left(C_{\text {Tris }}^{\circ}-C_{\text {complex }}\right)}
$$

if values of current concentration are used instead of activity.

Complex concentration will be much less than the BDP concentration upon substantial constant excess of BDP in the experiment by the molar ratio method. The Benesi-Hildebrand method can be used to determine conditional stability constant under these conditions and $\mathrm{K}_{\mathrm{st}}$ is represented as the equation:

$$
\mathrm{K}_{\text {st }}^{\prime}=\frac{C_{\text {complex }}}{C_{\text {BDP }} \cdot\left(C_{\text {Tris }}^{\circ}-C_{\text {complex }}\right)}
$$

Where $\mathrm{C}^{\circ}{ }_{\mathrm{BDP}}=\mathrm{C}_{\mathrm{BDP}}$ that it follows from UV-spectra (table 1 ).

Complex concentration can be determined using absorption change at $\lambda=256 \mathrm{~nm}$ and the extinction coefficient due to the salt complex formation in accordance with the Bouguer-Lambert-Beer law.

$\mathrm{C}_{\text {complex }}=\Delta \mathrm{A} / \varepsilon \cdot d$, where $d$-cuvette thickness.

Taking into account equations (4) and (5) the Benesi-Hildebrand equation takes the form:

$$
\frac{\mathrm{C}_{\mathrm{BDP}}^{\circ} \cdot \mathrm{d}}{\Delta \mathrm{A}}=\frac{1}{\varepsilon^{\prime}}+\frac{1}{\mathrm{~K}^{\prime} \mathrm{st} \cdot \varepsilon} \cdot \frac{1}{\mathrm{C}_{\mathrm{Tris}}^{\circ}}(6),
$$

Where $\Delta \mathrm{A}=\mathrm{A}{ }^{\circ}{ }_{\text {BDP }}-\mathrm{A}_{\text {current }} \mathbf{B D P}\left(\mathrm{in}\right.$ over the range $\alpha=\mathrm{n}_{\text {Tris }} / \mathrm{n}_{\text {BDP }}$ from 0.1 to 1.0 );

$\mathrm{C}^{\circ}{ }_{\mathrm{BDP}}$-initial BDP concentration equal to $4.9 \cdot 10^{-4} \mathrm{M}$;

$d$ is equal to $1 \mathrm{~cm}$.

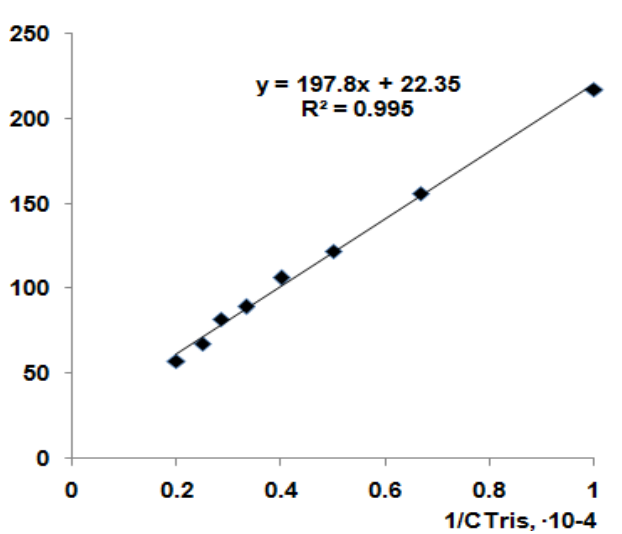

Fig. 14: Graphical solution of the equation (6)

The conditional stability constant $K^{\prime}{ }_{\text {st }}$ of the salt complex is $1130 \pm 55$ $\mathrm{mol} \cdot \mathrm{l}^{-1}$ that was solved graphically using the dependence of $\mathrm{C}{ }^{\circ}{ }_{\mathrm{BDP}} / \mathrm{A}$ on $1 / \mathrm{C}^{\circ}$ Tris (fig. 14 ).

The effective molar absorption coefficient of the salt complex $\varepsilon^{\prime}$ in accordance with the equation (6) is $422 \mathrm{l} \cdot \mathrm{mol}^{-1} \cdot \mathrm{cm}^{-1}$ which probably corresponds to the difference of the molar absorption coefficients of initial BDP and the salt complex. Since the molar ratio of initial BDP is $746 \mathrm{l} \cdot \mathrm{mol}^{-1} \cdot \mathrm{cm}^{-1}$ the molar absorption coefficient of the complex is probably $324 \mathrm{l} \cdot \mathrm{mol}^{-1} \cdot \mathrm{cm}^{-1}$. This value is close to the calculated dependence $A=f(\alpha)$ in the plateau region where $A=0,190$ (fig. $9 b$ ): $\varepsilon$ is $380 \mathrm{l} \cdot \mathrm{mol}^{-1} \cdot \mathrm{cm}^{-1}$ at the concentration of initial BDP is $5 \cdot 10^{-4} \mathrm{M}$.

So BDP may form various complexes with amines both of salt character, for example, with Tris and inclusion complexes, for example, with DA. In the second case, BDP carries out a role of drug delivery for readily oxidized drugs or high-toxicity substances.

In the present study we have characterized antioxidant activity of BDP and its complexes with readily oxidized DA and combination BDP-Tris complex with high toxicity cytostatics by biochemical indexes such as MDA level, SOD and LDH activities as evaluation criterion of energy metabolism.

It has been shown that the lipoperoxidation intensity (by the level of MDA) was reduced by half under the action of BDP-Tris complex as compared to the control and increased the SOD activity by $30 \%$ (table 5).

Table 5: Biochemical parameters under the influence of $2 \mu \mathrm{g} \cdot \mathrm{ml}^{-1} \mathbf{0 . 5 \%}$ aqueous solution of complex BDP-trisamine and its mixture with 5-fluorouracil (5-FU) or hydrazine sulfate (HS)

\begin{tabular}{llll}
\hline Parameters & Control, \% & & \\
\cline { 2 - 4 } & BDP-trisamine complex & (BDP-trisamine complex)+5-FU & (BDP-trisamine complex)+HS \\
\hline MDA $_{\text {plasma }}$ & 98.8 & 13.0 & 12.9 \\
MDA $_{\text {erythrocyte }}$ & 57.0 & 14.0 & 10.7 \\
SOD & 128.4 & 115.7 & 204.8 \\
LDH $_{\text {direct }}$ & 99.2 & 100.4 & 122.6 \\
LDH $_{\text {reverse }}$ & 154.2 & 105.7 & 294.8 \\
\hline
\end{tabular}

At the same time, it was found that BDP-Tris complex regulated energy metabolism in the cell. LDH activity remained practically unchanged in the direct reaction under the action of BDP-Tris complex whereas LDH activity in the reverse reaction increased by half.

There was a significant improvement in biochemical indexes in case of the combination of the toxic cytostatics such as 5-fluorouracil, hydrazine sulfate with BDP-Tris complex at a dose of $2 \mu \mathrm{g} / \mathrm{ml}$.
High antioxidant activity that established by the level of MDA in erythrocytes and by catalase activity in experiment in vitro for the solutions of BDP-amine complexes was demonstrated.

The effectiveness of the BDP-DA complexes is dose-dependent in phosphate buffer pH 6.86 under conditions close to physiological. The MDA level was decreased by half at a dose of $5 \mu \mathrm{g} / \mathrm{ml}$ under BDP action whereas the BDP-DA complex decreased the MDA level at a dose of $2 \mu \mathrm{g} / \mathrm{ml}$ (fig. 15, 16, table 6). 


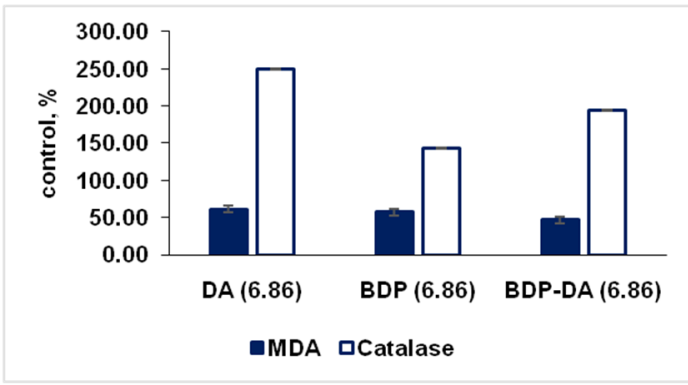

Fig. 15: Altering of MDA level and catalase activity by using $2 \mu \mathrm{g} / \mathrm{ml}$ DA, BDP and their mixture in phosphate buffer

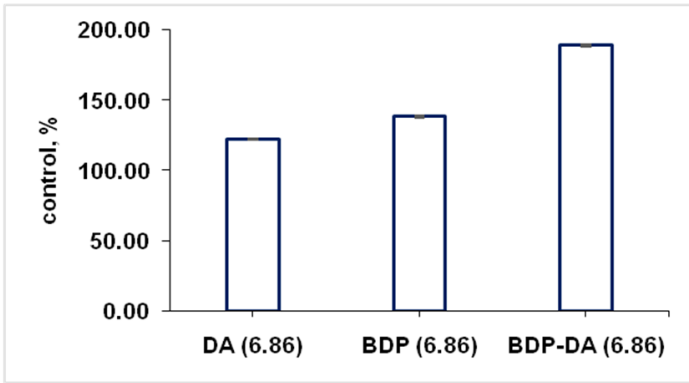

Fig. 16: Altering of catalase activity by using $5 \mu \mathrm{g} / \mathrm{ml}$ DA, BDP and their mixture in phosphate buffe

Table 6: Biochemical indexes of DA, BDP and their mixture in phosphate buffer

\begin{tabular}{|c|c|c|c|c|c|c|c|c|c|}
\hline \multirow[t]{4}{*}{ Sample } & \multicolumn{9}{|c|}{ Control, \% } \\
\hline & \multicolumn{3}{|c|}{ MDA level in erythrocyte } & \multicolumn{3}{|c|}{ MDA level in plasma } & \multicolumn{3}{|c|}{ Catalase activity } \\
\hline & \multicolumn{9}{|c|}{ Dose, $\mu \mathrm{g} / \mathrm{ml}$} \\
\hline & 2 & 5 & 10 & 2 & 5 & 10 & 2 & 5 & 10 \\
\hline $\mathrm{DA}^{*}$ & 61.8 & 46.2 & 82.3 & 200.0 & 200.0 & 169.2 & 249.8 & 122.5 & 129.9 \\
\hline $\mathrm{BDP}^{* *}$ & 57.6 & 43.7 & 82.3 & 215.4 & 207.7 & 169.2 & 142.8 & 138.4 & 129.9 \\
\hline $\mathrm{BDP}_{-} \mathrm{DA}^{* * *}$ & 47.0 & 67.7 & 78.6 & 153.9 & 176.9 & 115.4 & 194.2 & 189.1 & 144.4 \\
\hline
\end{tabular}

${ }^{*} 1.6 \mu \mathrm{g} / \mathrm{ml} \mathrm{DA} ;{ }^{* *} 1.25 \mu \mathrm{g} / \mathrm{ml}$ BDP (pH 6.86, phosphate buffer); ${ }^{* * *}$ solution of $1.6 \mathrm{mg}$ DA into $1 \mathrm{ml}$ BDP (molar ratio 4:1)

Along with this, the catalase activity increased under the same conditions for the BDP-DA complex at doses of 2 and $5 \mu \mathrm{g} / \mathrm{ml}(194$ and $189 \%$, respectively), which is higher than the catalase activity for BDP at the same doses (143 and 138\%, respectively).

The effect of $0.125 \%$ BDP aqueous solution on erythrocytes led to decrease the MDA level only at a dose of $10 \mu \mathrm{g} / \mathrm{ml}$ whereas catalase activity doubles at a dose of $5 \mu \mathrm{g} / \mathrm{ml}$. The antioxidant activity of the BDP-DA complex in water was stronger than for BDP that appears in the decrease of MDA level in erythrocytes up to $79 \%$ at a dose of $5 \mu \mathrm{g} / \mathrm{ml}$ and the increase of catalase activity for all doses (table 7, fig. 17)

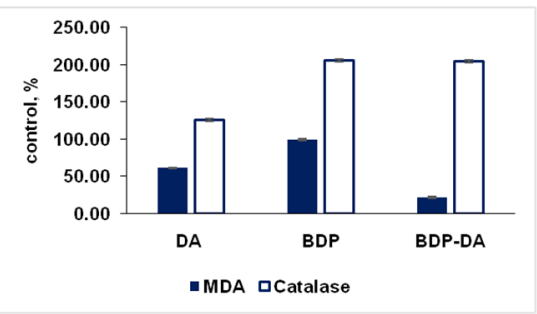

Fig. 17: Altering of MDA level in erythrocyte and catalase activity by using $5 \mu \mathrm{g} / \mathrm{ml}$ DA, BDP and their mixture.

Table 7: Biochemical indexes of DA, BDP and their mixture in water

\begin{tabular}{|c|c|c|c|c|c|c|c|c|c|}
\hline \multirow[t]{4}{*}{ Sample } & \multicolumn{9}{|c|}{ Control, \% } \\
\hline & \multicolumn{3}{|c|}{ MDA level in erythrocyte } & \multicolumn{3}{|c|}{ MDA level in plasma } & \multicolumn{3}{|c|}{ Catalase activity } \\
\hline & \multicolumn{9}{|c|}{ Dose, $\mu \mathrm{g} / \mathrm{ml}$} \\
\hline & 2 & 5 & 10 & 2 & 5 & 10 & 2 & 5 & 10 \\
\hline DA & 69.7 & 60.9 & 79.8 & 153.8 & 130.8 & 161.6 & 225.5 & 125.5 & 162.4 \\
\hline BDP & 79.4 & 99.2 & 33.6 & 161.5 & 161.6 & 184.5 & 140.2 & 205.9 & 142.3 \\
\hline BDP-DA & 58.0 & 21.4 & 59.7 & 155.2 & 192.3 & 123.1 & 223.7 & 204.5 & 200.5 \\
\hline
\end{tabular}

\section{CONCLUSION}

Thus, in this work we have shown that BDP is capable to form various complexes with amines having a high antioxidant activity. It is expected that the BDP complexes were developed due to salt formation and non-specific non-covalent binding. It has been noted that the stoichiometry of BDP complexes with DA was equal to 2:1 and 4:1 just as the stoichiometry of BDP-Tris complexes was 1:1.

The BDP and its complexes exhibited a stronger antioxidant effect in comparison with the initial BDP both in water and phosphate buffer that approved the decrease of MDA level and two-fold increase catalase activity at all doses. It should be noted that the studied compounds showed a significant prooxidant effect in plasma.

\section{AUTHORS CONTRIBUTION}

The authors' contribution is equivalent

\section{CONFLICT OF INTERESTS}

Declared none

\section{REFERENCES}

1. Pradere U, Garnier-Amblard EC, Coats SJ, Amblard F, Schinazi RF. Synthesis of nucleoside phosphate and phosphonate prodrugs. Chem Rev 2014;114:9154-218.

2. Hao HX, Wang JK, Wang YL. Solubility of dexamethasone sodium phosphate in different solvents. J Chem Eng Data 2004;49:1697-8.

3. Shamsuddin AM. Anti-cancer function of phytic acid. Int J Food Sci Technol 2002;37:769-82.

4. Gu M, Raina K, Agarwal C, Agarwal R. Inositol hexaphosphate downregulates both constitutive and ligand-induced mitogenic and cell survival signaling, and causes caspase-mediated apoptotic death of human prostate carcinoma PC-3 cells. Mol Carcinog 2010;49:1-12.

5. Chrobak E, Bębenek E, Kadela-Tomanek M, Latocha M, Jelsch C, Wenger E, et al. Betulin phosphonates; synthesis, structure, and cytotoxic activity. Molecules 2016;21:1123-35.

6. Krasutsky PA, Carlson RM, Karim R, Inventors. Regents of the University of Minnesota, assignee. Triterpenes having antibacterial activity. US Patent 6,689,767; 2004. 
7. Krasutsky PA, Carlson RM, Karim R, Inventors. Naturtek, LLC, assignee. Triterpenes having human antifungal and antiyeast activity. US Patent 6,642,217B2; 2003.

8. Muhammad A, Carlson RM, Reza-Ul Karim M, Krasutsky P. Inhibition of epstein-barr virus by the triterpenoid betulin diphosphate and uvaol. J Microbiol Biotechnol 2004;14:1086-8.

9. Kaplun AP, Andija-Pravdivyi JE, Bureeva SV, Kozlov LV, Shvets VI. Inventors moscow state academy of fine chemical technology named after lomonosov MV, assignee. The derivatives of betulin as inhibitors of the complement system. RU Patent 2,243,233; 2004.

10. Metzler D. Biochemistry: the chemical reactions of living cells. $2^{\text {nd }}$ ed. New York: Academic Press; 2003.

11. Cotton FA, Day VW, Hazen EE, Larsen S. Structure of methylguanidinium dihydrogen orthophosphate. Model compound for arginine-phosphate hydrogen bonding. J Am Chem Soc 1973;95:4834-40.

12. De Stefano C, Giuffre O, Milea D, Sammartano S. Speciation of phytate ion in aqueous solution. Non covalent interactions with biogenic polyamines. Chem Speciation Bioavailability 2002;15: 29-36.

13. Kallet RH, Jasmer RM, Luce JM, Lin LH, Marks JD. The treatment of acidosis in acute lung injury with tris-hydroxymethyl aminomethane (THAM). Am J Respir Crit Care Med 2000;161:1149-53.

14. Kislitsyn AN. Extractive substances of birch bark: Isolation, composition, properties, application. J Wood Chem Technol 1994;3:3-28.

15. Mihara M, Uchiyama $M$. Determination of malonaldehyde precursor in tissues by thiobarbituric acid test. Anal Biochem 1978;86:271-8.

16. Solovyeva AG, Zimin YV. A new estimation method of blood metabolism dynamics of patients with heat injures. Modern Technologies Med 2012;2:116-7.

17. Waterborg JH, Matthews HR. The lowry method for protein quantitation. Methods Mol Biol 1994;32:1-4.

18. Solovyev ME, Solovyev MM. Computer chemistry. Moscow: SOLON-Press; 2005. 